\title{
Green Bonds Issuance and Stakeholders Governance
}

\author{
Hiroshige Tanaka*1 and Chiharu Tanaka ${ }^{2}$ \\ ${ }^{1}$ Professor Emeritus of Chuo University, Tokyo, Japan \\ ${ }^{2}$ Manager, Mitsubishi UFJ Kokusai Asset Management Co., Ltd., Tokyo, Japan
}

Submission: July 09, 2021; Published: July 22, 2021

"Corresponding author: Hiroshige Tanaka, Professor Emeritus of Chuo University, Tokyo, Japan

\begin{abstract}
By issuing green bonds, global societies attempt to solve some critical problems overflowing from noneconomic spheres such as regional governance, social security to be weakened by COVID-19 pandemic and climate change issues. Green bonds issuance occurs in a process of the digital industrial revolution and is expected to be effective for construction of sustainable community but unavoidably brings structural changes of stakeholders. We should explore the sustainable scheme of green bonds as well as the effect of each investment project so that green bonds can solve extensive problems of climate change and social infrastructure. The theoretical analysis of multi stakeholders provides some cooperative financial schemes to develop green bonds issuance. Empirical explorations verify the theoretical results. A definition presented by Chinese green bond market proves to bring a restrictive framework for inside stakeholders to increase the issuance of green bonds and to promote construction of social infrastructures. However, the green bonds issuance in some emerging countries or regions has been developed openly with cooperation of outside stakeholders.
\end{abstract}

Keywords: Green bonds issuance; Digital industrial revolution; Sustainability; Inside stakeholders; Outside stakeholders

\section{Introduction}

To achieve low carbon societies, we should promote projects of renewable energies, energy efficient buildings and electric vehicles. The projects to mitigate climate change problems are expected to have higher initial costs and business risks but indicate lower running costs than their high carbon alternatives. The climate change issues have become to be targeted commonly in global communities. Green projects purpose to solve various environmental and sustainability problems. The green projects inevitably need a great amount of funds and are financed by governmental as well as private funds ${ }^{1}$. The large environmental projects must not only effectively achieve low carbon emission but also efficiently construct a scheme of sustainable governance. It is supposed that green bonds could cover suitably and cooperatively the investment gap for sustainable communities.

Since the 1990s, global markets have been enlarged mainly by dynamic competition in the growing world market and rising innovation of ICT. The industrial revolution derived from innovation of ICT influences many fields from manufacturing to performances of financial service industries. The revolution significantly has changed the lifestyles of residents beyond the reconstruction of industrial structures. The great changes of economies and societies are expressed by digitalization of global communities.

For examples, smart cities could improve in a process of digitalization of economies. By mobilizing benefits of the digitalization, the global communities should attempt to overcome cooperatively some global problems such as Climate Change and COVID-192 $[1,2]$. To achieve sustainability the global communities must be involved with problems of government and market failures at a global level. The preventing policies for inflection spread of COVID-19 require each region to recover serious damages of the pandemic and global communities to restore safety network of health. Climate Change problems have revealed various natural disasters in many regions. In the process of globalization many neo liberalists had an optimistic view that enlarging market

${ }^{1}$ Scaling up Green Bond Markets for Sustainable Development, Climate Bonds Initiative,2015 p.3. UNEP (The United Nations Environment Program) estimates annual gap of investment of 1 trillion USD for resilient environment in 2025-30.

Available in Green\%20Building\%20\&\%20Construction\%20Economics/GB-Public_Sector_Guide-Final-1A.pdf (Accessed 16 March 2021) 
economies could improve welfare of global societies. While the digitalization moves globalized economies into an integrated system, the social and environmental problems appear to disturb the development of market economies. Global market economies are more probable to increase peril lowering sustainability of society. To prevent great crises the globalized economies should construct sustainable scheme of communities positively ${ }^{3}$.

Since the decade of the 2010s, many corporations increase attempts to obtain benefits by connecting internet services ${ }^{4}$. Development of digital services reforms relations between corporation and stakeholders significantly. Corporations have become to turn the target from the price competition for market dominance brought by scale of production to efficient and prompt provision platform to correspond with diversified needs of services. Hindman [4] explores the relation between the digital economy and monopolies. Tanaka [5] theoretically discusses those behaviors of the major corporations leading the digital economy can be explored in the centralized schemes. The digitalization features enhancement of centralization of the economies and influence of stakeholders.

Employing the centralized scheme, Tanaka [6] focuses on the structural reform of stakeholders brought by the new industrial revolution. The feature of digitalization in economies and societies is explored by structure of stakeholders that are classified into inside, outside and external stakeholders. Each type of stakeholders participates communication scheme of the corporation with its own distinctive way. The digital industrial revolution reforms structure of stakeholders by accompanying the change of the communication system in global and local communities. The corporation cordially obeys the stable contacts with many stakeholders in markets and institutional relations but is possible to bring occasional connections with other stakeholders. The former stakeholders are referred as the inside stakeholders and the latter are stated by the outside stakeholders. Generally, the inside stakeholders present regular customers, business partners and employees. In green bonds issuance, the inside stakeholders imply cohesive relationships in the green projects. The outside stakeholders can connect more occasionally and freely with the corporation than the inside stakeholders. In the context of the green bonds the inside stakeholders exhibit a related organization including local governments and the outside stakeholders exhibit participants in the bonds market. Although the external stakeholders in bonds issuance are not directly concerned with the bonds market, they could improve own interests in social relations by enacting non economic initiatives such as regulations and legislations.

Development of ICT facilitates the communication between corporations and stakeholders and changes lives of the resident. The digital industrial revolution changes the feature of stakeholders in the market. However, some individuals who remain outside of the digital communication ${ }^{5}$ [7] cannot obtain enough benefit from the new industrial revolution. Tanaka [8] explores green projects in Chines communities by the voluntary contribution analysis of public goods. This paper theoretically explores the relation between structural changes of stakeholders and green bond issuance. This paper is organized in 7 sections. Section 2 focuses on the communication mechanism between the corporation and multi stakeholders in green bonds issuance is summarized as follows. The sustainable model analyses for global communities are applicable for issues of the green bonds project. Definition of green bonds influences the development of green projects. An empirical exploration on Chinese green bonds issuance indicates that the definition of green bonds determines dominant stakeholders in the market. It implies positively the relation between the volume and dominant stakeholders in green bonds issuance. Section 3 argues that the efficiency of green bonds issuance is suggested to be measured by the transaction costs of markets and societies. When total number of stakeholders is growing, the decreasing transaction cost of outside stakeholders induces the green bonds market to achieve sustainable communities.

Section 4 explores theoretically how the structural change of stakeholders influences green bonds issuance and brings the following results. Inside and outside stakeholders have incentives to increase payment from bonds issuance by improving efficiencies of communication. Consequently, the communication contribution of the stakeholders lowers transaction costs. If the digital industrial revolution raises more relative communication contribution of outside stakeholders than inside stakeholders, in the green bonds market issuance declines and prices rise. The composite system of green bonds aims to provide fund for needs of different stakeholders at the same time. The two definitions of China imply that green bonds finance domestic and global green projects and that the two ways of finance increases bonds issuance. The theoretical investigation implies that the internal networks of the corporation enhance the issuance volume of green bonds but that outside network of the corporation countervails the over issuance of green bonds. Section 5 demonstrates that the countries with undeveloped internal networks of finance depend on the outside network represented by the green bonds scheme

${ }^{2}$ Tanaka [1] provides a theoretical framework to achieve a sustainable governance of regions. By using second best solutions for regional sustainability, Tanaka [2] explores the relation between structural change of industries and sustainable governance of regions.

${ }^{3}$ Tanaka [3] demonstrates that a scheme to perform the principle of social responsibility brings sustainable corporate governance in global communities.

${ }^{4}$ In this paper, the bonds issuance is supposed to improve to take benefits from the efficient net work system that the digitalized economic and social systems construct.

${ }^{5} \mathrm{~A}$ part of exploration on the diversities in the social usability of digital technologies is brought by Choudrie, Tsatsou, Kruria [7]. 
financed with non-local currencies. These countries confront the problems brought by insufficient provision of fundraising.

Section 6 exhibits that the digitalization of green bond market grows the outside network. Rising outside stakeholders lower issuance by declining inside stakeholders in the over issuance of green bonds and increase issuance by alleviating outflow of inside stakeholders. Section 7 provides some empirical evidence to the theoretical exploration. The results comparatively notice that OECD countries obtain a different structure of stakeholders from non-OECD countries. Although fields of energy, buildings and transport occupy over $80 \%$ of green bonds in 2020 , the sustainable governance of the finance scheme is essential to perform long term investments.

The Green bonds project produces cooperative schemes with many stakeholders to achieve sustainable communities. This theoretical approach is derived from the research that Arrow [9] indicates CSR (Corporate Social Responsibility) as an issue of the economic theories. The theoretical framework is based on incentive theory of CSR that Tirole [10] explores on shareholder values. The sustainable framework of global communities needs to be funded by decentralized schemes. Tanaka [11] presents a theoretical model to analyze sustainability of the corporation with multi stakeholders. Tanaka [1-3] develop this theoretical model to explore sustainability of global communities ${ }^{6}[12]$. Tanka $[5,6]$ discuss that the new industrial revolution brought by globalization and digital innovation grows centralized frameworks in societies and economies. The significant concern of research becomes targeting sustainable decentralized mechanism to mitigate the market and the government failures brought by the centralized framework. Tanaka [13-15] evaluate social impacts of the new industrial revolution by relating with structural change of stakeholders. Tanaka [16] explains the implication of the Chinese definitions of green bonds issuance by basing on the theoretical model of stakeholders and explores fundamental issues of the digital innovation to achieve sustainable communities. This paper constructs general theory of sustainable financing framework and fucuses on the reform of stakeholders to grow green bonds issuance.

\section{Green Bond Definitions and Issuances}

Since the 2010s innovation of ICT propels to spread utilization of internets. The efficient economic systems are separated from scale merits of mass production. Corporations raise the opportunity to perform globally ${ }^{7}[17-22]$. Tanaka [6] demonstrates theoretically that digitalized economic systems are not able to improve social welfare without constructing sustainable schemes. Global communities could not develop economic and social systems without developing digital transformation and primarily should aim to achieve sustainable framework. The green bonds market is expected to solve climate change problems and to construct social infrastructures. This paper theoretically explores that the green bonds market is an effective scheme to improve sustainability of economies and societies.

Tanaka $[6,14]$ present a theoretical model to explore the structural changes of stakeholders and sustainable communities in the process of digital transformation of economies. The model exhibits a principal and agency model of game theories between the corporation and the stakeholders and is described as follows. The corporation obtains net private profit $\Pi(x)$ from issuing amount of green bonds $x$. The green projects are public and private cooperative projects by using the green bonds scheme with $\mathrm{n}$ stakeholders. Although green projects probably need a large amount of funds to provide environmental infrastructures, in the present, governments alone cannot finance the projects under the strict budgetary condition. It is possible that the green bonds project performs in negative net profits. However, green bonds issuance presents declining marginal net profit. The green bonds scheme executes environmental projects cooperatively with inside and outside stakeholders. By using the mathematical expression, the corporation makes payment $t_{i}$, such as wages, benefits and tax exemption, for each stakeholder $i$. The total payment $t$ describes the summation $t=\sum_{i=1}^{n} t_{i}$. As the green project might involve not only domestic but also overseas stakeholders, each stakeholder has distinct evaluation of the project. The benefit that the stakeholder i obtains from the green project is exhibited by evaluation function $v_{i}\left(x, t_{i}\right)$. The green project enhances industries developing renewable energy but depresses products massively consuming fossil fuels. To simplify the reasoning, the stakeholder $\mathrm{i}$ and $\mathrm{j}$ are classified into positive stakeholders, $\frac{\partial v_{i}}{\partial x} \geq 0$ and negative stakeholders, $\frac{\partial v_{j}}{\partial x}<0$. Spreading facilities of internet complete diversified connection between corporations and stakeholders. In particular, the digitalization of industries becomes to distinguish exactly positive and negative stakeholders. Consequently, digital transactions can require payments for positive stakeholders and offer benefits for negative stakeholders. The transaction pays prices for negative stakeholders and receives fees from positive stakeholders.

The development of Chinese green bonds projects illustrates an influence of stakeholders on sustainability of economic and social systems. Financial technologies have evolved greatly with innovation of ICT. Green bonds are probable to grow by facilitating the improving internet technologies to include offshore markets. Openly enlarging markets are required for trades to be fair and legitimate. However, green bonds market in China exhibits that the governance of the green bonds project can be explained by the theory of multi stakeholders. A report of Climate Bonds Initiatives

${ }^{6}$ Global Sustainable Investment Alliance 2019, [12] discusses the progressive development of sustainable governance in the global economies.

${ }^{7}$ Richardson, Nam [17] explain the reasons why globalized economies bring many shrinking cities. Many researchers discuss rising influences of the digital industries. Rifkin [18], Oskam [19], Paus [20], Cassiers, 8Maréchal, Méda D ed. ,[21 ] \& Baecker RM [22] explore the revolutionary changes in social systems to be brought by innovation of ICT. 


\section{Annals of Social Sciences \& Management studies}

(CBI) [23] describes issuance of labelled green bonds ${ }^{8}$ as follows. In 2019, China issued the largest source of labelled green bonds with USD55.8bn. However, according to ratification of the CBI Green Bond Database Methodology in 2019, USD31.3bn worth of Chinese green bonds clears both Chinese and CBI green definitions, while USD24.5bn of Chinese green bonds are only aligned with China's local green definitions. The feature of green bonds definition implies that China aims to improve the two types green bonds at the same time. The issuance of green bonds is supposed to reflect "dual circulation strategy" that China presents in $14^{\text {th }}$ five year plan (2021-25). Considering that this policy intends to raise domestic economy and to develop global activities, the theoretical model of stakeholders effectively exhibit how China needed to issue the two definitions of green bonds.

The stakeholders approach exactly prospects the development of green projects. To apply stakeholder analyses, the market of green bonds aligned by CBI rule is supposed to be organized by outside stakeholders. Corporations take various options to achieve sustainable governance. While some corporations positively perform transactions to follow global businesses rules, others mainly obey the rules in a large domestic market. In Chines green bond issuance, many large state-owned corporations cannot efficiently adapt rapidly changing global requirements of governance. The global standard of green bonds issuance requires to improve corporate governance in the domestic market. Even if green bonds issuance proceeds to obey CBI rule, inside and outside stakeholders in the bonds market grow unevenly. In the green bonds to improve the local infrastructure, the inside stakeholders are assumed to share positively the related profit with the corporation. The outside stakeholders could facilitate green bonds to improve sustainability of global communities by solving the problems of climate change. Inside and outside stakeholders participate green bonds market to seek their own merits. It is assured that the proportion of the two stakeholders influences green bonds issuance ${ }^{9}$.

The displacement of decentralized systems that negative stakeholders activate in the green bonds issuance improves sustainability of communities ${ }^{10}$. In the dual circulation strategy China should initiate a method for negative stakeholders to contribute on sustainable communities. In the mathematical model, the inside and outside stakeholders are exhibited by $1, \ldots, n_{0}$, and $n_{0}+1, \ldots, n_{1}$. The external stakeholders to activate the green bonds market are expressed by $n_{1}+1, \ldots, n$.

\section{Green bonds market in Growing Stakeholders}

The inside and outside stakeholders exhibit different communication needs for the green bonds issuance. Issuance of green bonds brings the inside stakeholders related benefits, such as rising employments and enhancing social infrastructures. The outside stakeholders seek to improve the scheme of sustainable governance in the bonds market. To achieve sustainable governance every stakeholder $i$ should contribute effort $y_{i}$ on the communication scheme. The stakeholder $i$ contributes to improve communication scheme. The total efforts are expressed by $y=\sum_{i=1}^{n} y_{i}$ and indicate efficiency of communication mechanism. Inside stakeholders obtain greater influence from green bonds issuance than outside stakeholders. When a green project cannot be financed by bonds, the green development will be suspended. Consequently, some inside stakeholders lose jobs but opportunities for investment partially disappear in outside stakeholders. The communication scheme indicates efficiency indexes by $\beta(x)$ for inside stakeholders and $\gamma(y)$ for the outside stakeholders. The inequality, $1>\beta(x)>\gamma(y)$ for any $x$, $y$ distinguishes implication of the two indexes. It is supposed to complete mathematical discussions that the two communication index functions are increasing with $x, y$ and that are satisfied with $\beta^{\prime}(x)>0$ and $\gamma^{\prime}(y)>0$. The increasing function with $x, \beta^{\prime}(x)>0$ implies that the corporation becomes more cooperative with the inside stakeholders as bonds issuance is rising.

As innovation of ICT with digital transactions becomes to recognize details of digital services, improving ICT makes possible to raise efficiency of communication $\gamma(y)^{11}$, regarding outside stakeholders. The efficiency is supposed to be an increasing function of $y, \gamma^{\prime}(y)>0$. As innovation of ICT raises the relative advantage of outside stakeholders, they attract member from other stakeholders. It is affordable that the structural change of stakeholders may alter the borders to classify stakeholders. The border numbers $n_{0}$ and $n_{1}$ are not constants but presented by functions $n_{0}(y)$ and $n_{1}(y)$ of variable $y$. To descry the borders more preciously, the net benefit function of the corporation is stated by $(1)^{12}$.

$$
N B=\Pi(\mathrm{x})+\beta(x) \sum_{i=1}^{n_{0}(y)}\left\{V i\left(x, t_{i}\right)-y_{i}\right\}+\gamma(y) \sum_{i=\mathrm{n}_{0(y)}}^{\mathrm{n}_{1}(y)}\left\{V_{i}\left(x, t_{i}\right)-y_{i}\right\}-\mathrm{t} .
$$

In sustainable communities the corporation must not consider only market conditions but also evaluations exhibited by related stakeholders. We should explore the integrated system of economies and societies to coordinate the corporation and stakeholders $^{13}$.

${ }^{9}$ The report [23] in page 3 indicates distinctive features of green bonds issuance in China.

${ }^{10}$ In researches of economic and social mechanisms, the digitalization improves communication between the corporation and stakeholders. While corporations perform in the centralized scheme, Tanaka [15] demonstrates that digitalization increases outside stakeholders by the transformation from other stakeholders.

${ }^{11}$ Tanaka [5] explains why the decentralized systems can improve sustainability of communities.

${ }^{11}$ Tanaka [6] describes the optimal contribution on communication scheme.

${ }^{12}$ This expression revises (2) in Tanaka [6] to be applicable for investigating green bonds issuance.

${ }^{13}$ The development of digital economies creates new types of the transaction of goods and services. The famous theory of Coase [24] suggests that new forms of contracts are derived from needs of communities. Corresponding to new wave of transaction, legislations and regulations are supplemented 


\section{Annals of Social Sciences \& Management studies}

The expression (1) exhibits that the development of green bonds issuance depends on social costs as well as net profit of the corporation. The social costs of green bonds issuance are burdened by both the corporation and stakeholders. The green bonds issuance brings the transaction cost as a social $\operatorname{cost}^{14}[25$ 27]. Transaction costs are different for each type of stakeholders. Tanaka [6] states the transaction costs of inside, outside and external stakeholders by $C_{i}, C_{0}, C_{e}$,

$$
\begin{aligned}
& C_{i}=1-\beta(x), \\
& C_{0}=1-\gamma(y), \\
& C_{e}=1 .
\end{aligned}
$$

The transaction costs indicate how digitalization of economies changes the green bonds market. The figure y denotes progress of digital industrial revolution. In the first step, as digital transformation is supposed to bring $\gamma^{\prime}(y)>0$, the transaction cost of outside stakeholders written by (3) is lowering with investment on digital technologies in green bonds issuance. The declining issuance cost of green bonds induces to raise volume of issuance. In the second, from the inequality $\beta^{\prime}(x)>0$, (2) implies that an increment of green bonds issuance brought by outside stakeholders declines transaction costs with inside stakeholders. Inside stakeholders take advantage of relatively low transaction costs. More inside stakeholders become to participate on the green bonds market. So the inside and outside stakeholders increase to be involved in green bonds market that social communication can enhance sustainability. The digital industrial revolution is one of driving forces to propel green projects and sustainability of communities.

However, it is possible that inside and outside stakeholders do not increase at the same time. Changes of relative transaction costs may induce stakeholders to choose an appreciate type of stakeholders and reform the structure of stakeholders. Tanaka [28] discusses that the transaction costs indicate an efficiency index of digital industrial revolution. The section 4 investigates the issuance of green bonds when structural changes of stakeholders occur.

\section{Bonds Issuance and the Structure of Stakeholders}

Rising green bonds market is expected to improve sustainability of global communities. The corporations to issue green bonds are extending from government agents to private organizations. To solve increasing fiscal deficits the government encourages finance with private funds. The green bonds market aims to ensure the cooperative scheme of sustainable governance with inside as well as outside stakeholders.

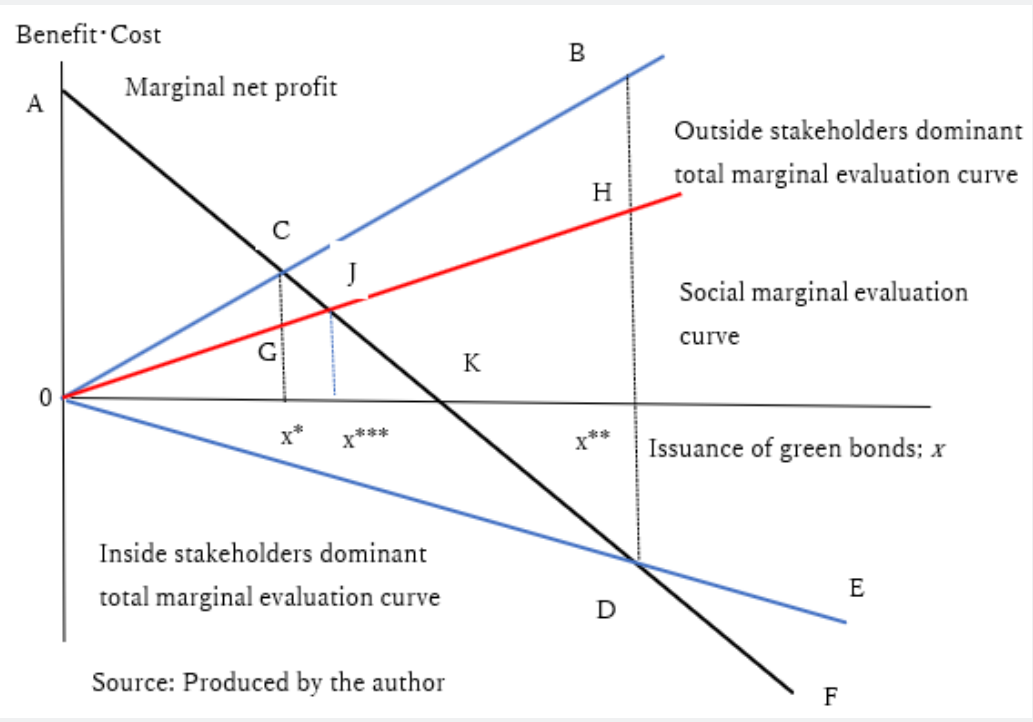

Figure 1: Green bonds issuance and dominance of stakeholders.

The performance of green bonds issuance is expressed by maximizing function (1) regarding $x, t_{i}\left(i=1, \ldots, \mathrm{n}_{1}\right)$. Differentiation of the function (1) with $\mathrm{x}$ brings the optimal condition of green bonds issuance by

$$
\frac{d \pi}{d x}=\sum_{i=1}^{\mathrm{n}_{0}(y)}-\left\{\frac{d \beta(x)}{d x}\left(V_{i}\left(x, t_{i}\right)-y_{i}\right)+\beta(x) \frac{\partial v_{i}\left(x, t_{i}\right)}{\partial x}\right\}-\gamma(y) \sum_{i=\mathrm{n}_{0(y)}}^{\mathrm{n}_{1}(y)} \frac{\partial v_{i}\left(x, t_{i}\right)}{\partial x} .
$$

The implication of (5) is illustrated by Figure 1. The left side means marginal net profit and is depicted by the curve AF. The

${ }^{14}$ This paper explores that the corporation cannot estimate completely evaluation of stakeholders. The estimation gaps make problems of green bonds issuance. The transaction costs clue issues of incomplete estimation in green bonds issuance by expanding the extend investigated by such as Williamson [25]- [27]. 
right side of (5) is divided into the first term to express marginal evaluation of inside stakeholders and the second term to indicate marginal evaluation of outside stakeholders. By excluding negative signs in (5), the first term presents positive, and the second term is negative. When the absolute value of the first term is greater than that of the second value, inside stakeholders dominate green bonds market. The dominance of inside stakeholders is depicted by the curve $0 \mathrm{E}$. When (5) is positive, outside stakeholders dominate the green bonds market. By the similar reasoning, the dominance of outside stakeholders is exhibited by the curve $0 \mathrm{~B}$. (5) indicates that the optimal issuance in the market that outside stakeholders dominate is $\mathrm{x}^{*}$ in the intersection point $\mathrm{C}$ of the curves $\mathrm{AF}$ and $0 \mathrm{~B}$. Similarly, the optimal issuance $\mathrm{x}^{* *}$ in green bonds market that inside stakeholders dominate is determined by the intersection point $\mathrm{D}$ of the curves $\mathrm{AF}$ and $0 \mathrm{E}$. The point $\mathrm{C}$ is exhibited in positive marginal net profit, while the point $\mathrm{D}$ appears in negative net profit. As marginal net profit curve is decreasing with green bonds issuance, $\mathrm{x}^{* *}$ is greater than $\mathrm{x}^{*}$. The green bonds market that issues $\mathrm{x}^{* *}$ is probable to obey the standards and practices confirmed by inside stakeholders. Outside stakeholders guided by global and sustainable standards aim to make issuance and governance more sustainable. We summarize the above investigation by the Proposition 1

i. Proposition 1. When inside stakeholders dominate the green bonds market, the project financed by the bonds is probable to take a risk of social welfare loss such as default. Outside stakeholders intend to reform the green bonds market so that global communities may achieve sustainability. Rising dominance of outside stakeholders in the bonds market lowers the issuance volume and arises the issuance price of the market.

Figure 1 shows that the point $\mathrm{D}$ with dominant inside stakeholders does not necessary bring social optimal issuance. So green projects become sustainable, that green bonds issuance should be ensured by CBI standard. As the value of (5) increasing, the optimal point $\mathrm{D}$ moves toward to point $\mathrm{J}$. It is noticed that the value of (5) depends on parameters $\beta(x), \gamma(y), \mathrm{n}_{0}(y)$ and $\mathrm{n}_{1}(y)$ as well as variables $x, t_{i}\left(i=1, \ldots, \mathrm{n}_{1}\right)$.. It is possible that scheme of green bonds issuance develops with a following wind in the digital industrial evolution. The improvement of communication systems between the corporation and stakeholders can bring the structural changes of stakeholders to bring sustainable communities.

The optimal conditions for payments are brought by differentiating (1) with $t_{i}(i=1, \ldots, \mathrm{n})$. . The optimal conditions of payments expressed by (6), (7) and (8) for stakeholders are distinguished for inside, outside and external stakeholders.

$$
\begin{aligned}
& \frac{\partial v_{i}\left(x, t_{i}\right)}{\partial t_{i}}=\frac{1}{\beta(x)}, \mathrm{i}=1, \ldots, \mathrm{n}_{0}(y) . \\
& \frac{\partial v_{i}\left(x, t_{i}\right)}{\partial t_{i}}=\frac{1}{\gamma(y)}, \mathrm{i}=\mathrm{n}_{0}(y)+1, \ldots, \mathrm{n}_{1}(y) .
\end{aligned}
$$

$$
t_{i}=0, \frac{\partial v_{i}(x, 0)}{\partial t_{i}}>0, \mathrm{i}=\mathrm{n}_{1}(y)+1, \ldots, n .
$$

The expression (8) states mathematically their boundary solutions for external stakeholders.

To explore social welfare, we define the social marginal evaluation by including the evaluation of the external stakeholders. The social marginal evaluation is defined to be written by the right side of the expression (9). The social optimal issuance of green bonds is the solution of (9).

$$
\frac{d \pi}{d x}=\sum_{i=1}^{n}-\frac{\partial v_{i}\left(x, t_{i}\right)}{\partial x} .
$$

In Figure 1 the social marginal evaluation is depicted by the curve $0 \mathrm{H}$. As the curve $0 \mathrm{H}$ is expressed with a weighted summation of the curves $0 \mathrm{~B}$ and $0 \mathrm{E}, 0 \mathrm{H}$ is located between $0 \mathrm{~B}$ and $0 \mathrm{E}$. The social optimal green bonds issuance $\mathrm{x}^{* * *}$ indicated by the intersection between curves $\mathrm{AF}$ and $\mathrm{OH}$ is greater than $\mathrm{x}^{*}$, where outside stakeholders dominate, and lesser than $\mathrm{x}^{* *}$, where inside stakeholders dominate.

\section{Restriction of Green Bonds Issuance with Insufficient}

\section{Inside Stakeholders}

In the previous section we explore that structure of stakeholders influences the issuance of green bonds. In the first, many emerging countries have not obtained enough inside stakeholders with adequate knowledge and funds for green projects. As green projects are expected to raise a large industries and social infrastructures for the regions, green bonds finance funds in some offshore markets. It is assumed that outside stakeholders dominate the green bonds market. Marginal evaluation curve in the offshore market financing green bonds is approximately exhibited by curve $0 \mathrm{~B}$. The market issuance $\mathrm{x}^{*}$ is lesser than the social issuance $\mathrm{x}^{* * *}$ and the social welfare loss is expressed by the area of triangle CGJ. The offshore green bonds market accompanied with immature domestic finance brings under issuance. The green bonds issuance dominated by outside stakeholders is not expected to provide enough green projects for sustainability.

Many advanced countries possibly present dominant appearance of inside stakeholders. Because legislation and regulation are incomplete, outside stakeholders do not participate green bonds market actively. In situation with the dominant inside stakeholders, Figure 1 approximates the social evaluation curve by curve $0 \mathrm{E}$. Some local governments are expected to raise budget revenues from increased production of the corporation. The local governments become positive stakeholders. Although the corporation issues green bonds beyond the maximized profit point $\mathrm{K}$, the local governments can compensate the decrement of profit for the corporation indicated by the area of the triangle $0 \mathrm{DK}$, because they gain a remaining benefit beyond the payment by the triangle $\mathrm{KDx}^{* *}$. The intensive interests that the corporation 
and small members of inside stakeholders share bring incentives to issue more green bonds beyond social optimal amount $\mathrm{x}^{* * *}$ to $\mathrm{x}^{* *}$. The problem of over issuing green bonds is exhibited by social welfare loss indicated by the area of the triangle JDH. As the welfare losses include failures or defaults of green projects, faire and transparent rules aim to reduce the losses by participating with various outside stakeholders.

The above investigation discusses that sustainable issuance of green bonds could achieved by properly designed cooperation with inside and outside stakeholders and is summarized by Proposition 2.

ii. Proposition 2. Green bonds projects which are dominated by outside stakeholders issue less volume and higher rate of bonds than social optimal issuance. In this situation, growing inside stakeholders in green bond market could decline the social welfare losses on green projects. However, the green bonds market dominated by inside stakeholders probably issue green bond more beyond the social optimal amount. Rising participation of outside stakeholders contribute to construct a sustainable framework of green bonds.

\section{CBI global definition and transformation of stake- holders}

The previous sections 4 and 5 explore that the dominance of inside stakeholders or outside stakeholders brings over or under issuances of green bonds. The result implies that initiatives to transform properly stakeholders could decrease social welfare losses. Tanaka [15] argues that the digitalization of economies and societies influences differently incomes of stakeholders. Surpluses indicated in Figure 2 exhibit the transformation of stakeholders. It is supposed that inside stakeholders are organized less various than outside stakeholders. Inside stakeholders obtain the steeper marginal evaluation curve $\mathrm{CD}$ with payment than the counterpart curve $\mathrm{AB}$ with outside stakeholders. Considering that external stakeholders are connected more loosely with the corporation than other stakeholders, their marginal evaluation curve $\mathrm{FK}$ is located lower than the two curves $\mathrm{CD}$ and $\mathrm{AB}$.

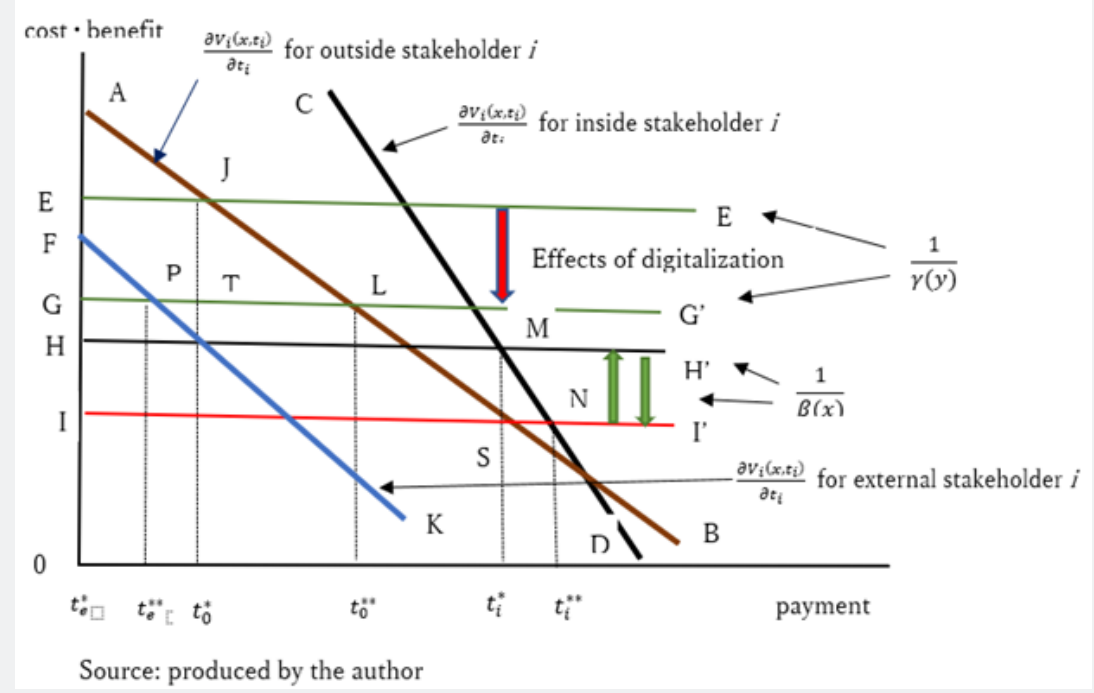

Figure 2: Digital industrial revolution and incentives for stakeholders to move.

In the first, it is assumed that over issuance $\mathrm{x}^{* *}$ of green bonds in Figure 1 is brought by dominant inside stakeholders. As expression (5) is negative, marginal net profit is lowering. The corporation reduces issuance $x$ without compensating support of inside stakeholders. Decreasing issuance lowers $\beta(x)$ and shifts the line II' expressed by expression (6) upward to line HH'. However, digital industrial revolution implies increasing contribution y. Considering expression (7) and $\gamma^{\prime}(y)>0$, the line EE' moves downward to GG'. Consequently, inside stakeholders loss the surplus presented by the area of the triangle MSN and outside stakeholders gain the surplus expressed by the area of the triangle JTL. So inside stakeholders such as local governments do not go into default, that they turn into outside stakeholders to decrease risks. In particular, the municipalities alone would not like to propel governmental green projects, and plan to enlarge cooperative scheme with private funds. The marginal evaluation curve $C D$ of inside stakeholders is altered by the curve $A B$ of outside stakeholders. When the line EE' moves downward the line GG', external stakeholders become to satisfy (7) instead of (8) and to gain the surplus indicated the area of the triangle FGP. If they achieve own aims, they are willing to turn into outside stakeholders. For example, when the bonds market is available with low risk, NPO purchases green bonds to achieve purposes of the organization. The external stakeholder gains benefits by behaving like outside stakeholders. Consequently, the outside stakeholders grow by flows from other stakeholders. Figure 1 illustrates that over issuance of green bond $x^{* *}$ approaches to social optimal issuance $\mathrm{x}^{* * * 15}$. 


\section{Annals of Social Sciences \& Management studies}

In the second, it is assumed that under issuance $x^{*}$ of green bonds presented in Figure 1 is brought by the dominance of outside stakeholders. This situation means that the domestic bonds market is immature. As the dominance of outside stakeholders expresses positive marginal net profit of (5), the domestic market financing could raise market issuance of green bonds. In Figure 2, rising $x$ shifts the line HH' downward to the line II' by raising $\beta(x)$. Figure 2 exhibits also that increasing issuance of green bonds brings inside stakeholders the surplus indicated by the area in the triangle MSN. Considering that the difference between the two surpluses with inside and outside stakeholders exhibit closer in under issuance than in over issuance, the flow from inside stakeholders to outside stakeholders becomes to be smaller amount than in over issuance situation and facilitates to achieve the social optimal issuance $\mathrm{x}^{* * *}$. However, in the under issuance of green bonds the flow from external stakeholders to outside stakeholders continues as in over issuance situation. The investigation of this section is summarized in Proposition 3.

iii. Proposition 3. Digital industrial revolution brings the structural transformation of stakeholders. The scheme that moves inside and external stakeholders into outside stakeholders is effective to solve problems of the over issuance of green bonds. The initiatives to grow inside as well as outside stakeholders aim to solve the problems of under issuance of green bonds.

\section{Outside stakeholders in the green bonds market and emerging countries}

Green bonds financing is expected to contribute on sustainability of local communities. And many schemes of green bonds could be formed by a global cooperation. Inside and outside stakeholders positively cooperate to the green project. If the green project cannot obtain abundant funds with inside stakeholders in domestic financial market, it should find outside stakeholders overseas to seek sustainable communities. This section explores an empirical evidence in the green bonds project to form the cooperative mechanism with inside and outside stakeholders. The exploration proceeds as follows.

This section produces Figures $3 \& 4$ by processing the numerical data to be provided by Bloomberg L.P. ${ }^{16}$. Some figures regarding green bonds which are not available on the above the data source are excluded from the following investigation. This section explores all active green bonds including government and corporate bonds in this analysis. It is noticed that the securities are defined by green bonds in this date source. The values of bonds and exchange rates are estimated in 2 April, 2021. The values of bonds are calculated by USD. To compare domestic and offshore markets of green bonds issuance, we classify the green bonds according to issuances by local currencies or non-local currencies. Bonds applicants by local currencies are supposed to include inside and outside stakeholders in domestic and overseas investors. On the contrary, applicants by non-local currencies are assumed to present mainly outside stakeholders. In the previous sections we assume that the immature development of inside stakeholders regarding green bonds enhances issuances in offshore markets and that digitalization of industries facilitates transaction of outside stakeholders. To aim at exploring the implication, countries or regions which issuing identities belong to are classified into Economic Co-operation and Development (OECD) countries and non-OECD countries. As a side note, the green bonds issued by supranational organizations (SNAT) are excluded from the investigation in this section.

Table 1: Green Bond Issuance of Domestic and Offshore Markets.

\begin{tabular}{|c|c|c|}
\hline & non-Local currencies & Local currencies \\
\hline OECD countries & 191,197 & 583,631 \\
\hline non-OECD countries & 107,922 & 103,247 \\
\hline & & US million dollars \\
\hline
\end{tabular}

Source: produced by the author

This section provides the empirical foundation on the theoretical exploration in the sections 3 to 5 . The performance of stakeholders in green bonds finances is measured by classifications of applicants in the green bonds market. Figure 3 exhibits that OECD countries issue green bonds mainly in the domestic financial markets. However, Figure 4 indicates that nonOECD countries issue greater volume of green bonds than OECD countries in offshore financial markets. The results present a significant implication of green bonds issuance. The two figures show an impressive contrast of green financial markets. However, Proposition 1 demonstrates that the digital industrial revolution brings enhancing influence of outside stakeholders on the green bonds project in both OECD and non- OECD countries. In Figure 3 , the domestic financial market is dominant in OECD countries. Since development of digital technologies grows outside stakeholders, the transaction of local currencies is possible to be carried by outside stakeholders. Table 1 shows that OECD countries contain about 3 times issuance of local currencies than of non-local currencies. Although we do not obtain a complete proof now, it provides an evidence that rising issuance of green bonds accompanies growth of inside stakeholders. Investigation of the section 4 indicates a reason of dominating bonds issuance by local currencies in Figure 3. Figure 4 shows that issuance of green bonds brings cooperation with large number of outside stakeholders overseas. To lower charge for risks, green projects financing green bonds are required to implement the global standard of issuance.

${ }^{15}$ Tanaka [16] explores the flow of stakeholders brought by digital industrial revolution but fucuses on issues of the under issuance of green bonds to develop green projects.

${ }^{16}$ The figures are calculated by basing the source to be accessed on 2 April,2021. The definition of green bonds stated in BNEF_Green-Bonds-TerminalGuide_H2-2015-update.pdf (accessed 9 July 2021) 

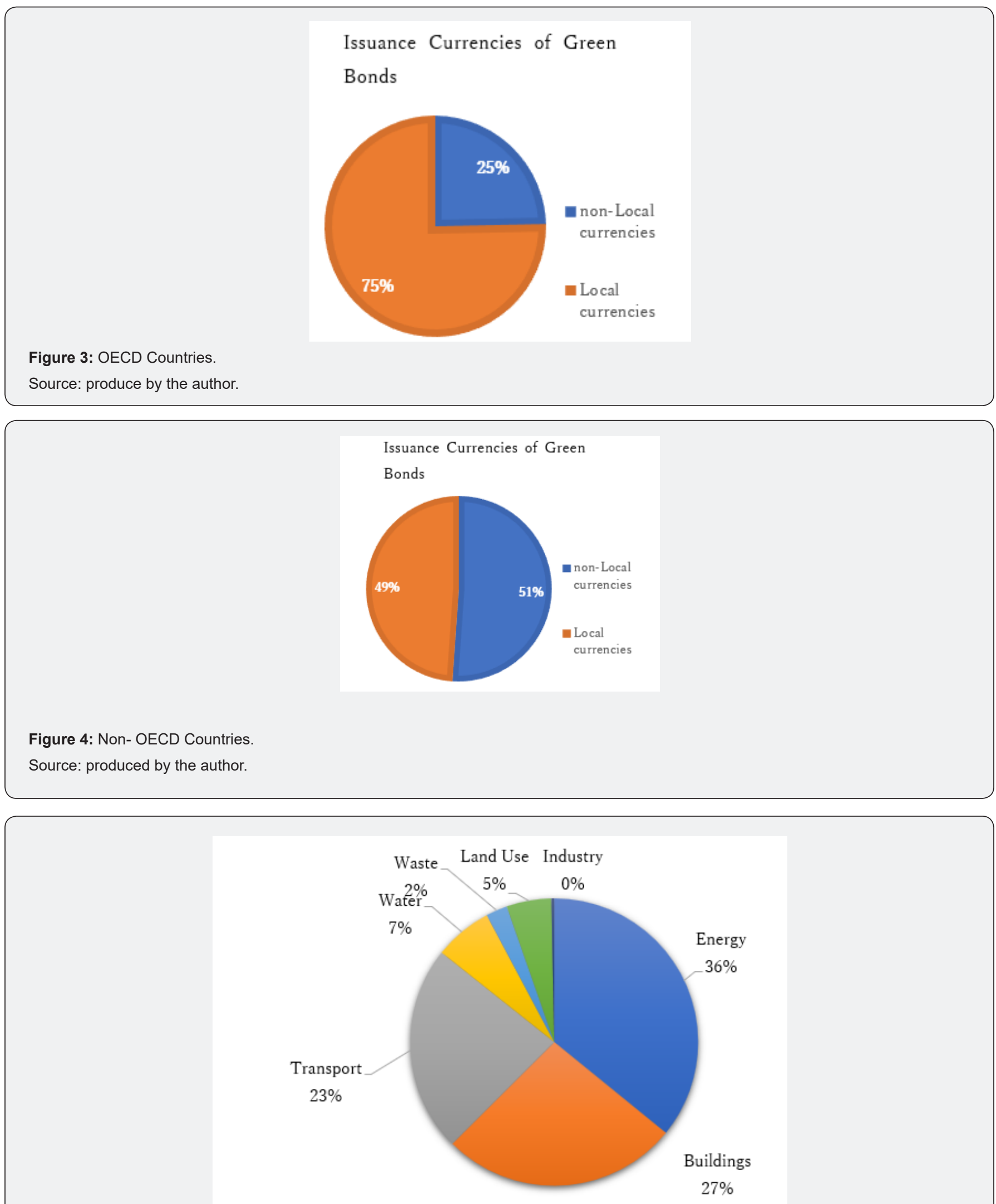

Figure 5: Use of Proceeds by Amount Issued (2020).

Source: Climate Bonds Initiative, Green Bonds Data Platform. 


\section{Annals of Social Sciences \& Management studies}

Climate Bonds Initiative publicly presents the recent data of green bonds issuance ${ }^{17}$ to enhance the environmental finance. Figure 5 exhibits that labelled green bonds are facilitated largely for the investment of projects with energy, buildings and transport.

Table 2 shows uses of labelled green bonds in 2014-20. By considering that the total annual issuance increases eightfold in this period from 35.6 (US bln) in 2014 to 286.2 (US bln) in 2020, it is possible to conclude that green bonds effectively lower the emission of carbon and construct sustainable infrastructures. To achieve low carbon societies, the needs of environmental investment are increasing. When one government is not possible to finance the large low carbon projects, a cooperative scheme needs to perform the environmental financing. Sustainable global communities inevitably involve the efficient scheme to prevented green bonds form defaulting.

Table 2: Climate Bonds Initiative -Use of Proceeds by Amount Issued (2014-2020).

\begin{tabular}{|c|c|c|c|c|c|c|c|}
\hline & $\mathbf{2 0 1 4}$ & $\mathbf{2 0 1 5}$ & $\mathbf{2 0 1 6}$ & $\mathbf{2 0 1 7}$ & $\mathbf{2 0 1 8}$ & $\mathbf{2 0 1 9}$ & $\mathbf{2 0 2 0}$ \\
\hline Energy & 18.4 & 23.7 & 33.8 & 53 & 53.8 & 84.2 & 102.7 \\
\hline Buildings & 7.4 & 7.2 & 16.6 & 44.1 & 47.1 & 79.6 & 76.2 \\
\hline Transport & 4.2 & 6 & 12.6 & 24 & 30.7 & 52.7 & 66.4 \\
\hline Water & 2.9 & 4 & 10.8 & 20.6 & 20.4 & 25 & 18.7 \\
\hline Waste & 1.2 & 1.6 & 4.5 & 6.2 & 7.6 & 9.9 & 6.9 \\
\hline Land Use & 1.5 & 0.6 & 1.7 & 5.2 & 7.4 & 9.1 & 14.4 \\
\hline Industry & & 0.7 & 0.1 & 0.2 & 0.8 & 1.9 & 0.9 \\
\hline Total & 35.6 & 43.8 & 80.1 & 153.3 & 167.8 & 262.4 & 286.2 \\
\hline & & & & $\begin{array}{c}\text { US billion } \\
\text { dollars }\end{array}$ & & & \\
\hline
\end{tabular}

Source: Climate Bonds Initiative, Green Bonds Data Platform.

\section{Acknowledgment}

Tanaka, $\mathrm{H}$ organizes this paper and produces the section 1 -6. Tanaka, C. explores empirically and the statistical calculation in the section 7. The views and opinions expressed herein are those of the author and do not necessarily reflect the views of the Company, its affiliates, or its employees.

\section{References}

1. Tanaka H (2017) Sustainability of Global Communities and Regional Risk Governance. Asia Pacific Journal of Regional Science 1: 639-653.

2. Tanaka H (2018) Mechanism of Sustainability and Structure of Stakeholders in Regions. Financial Forum 7(1): 1-12

3. Tanaka H (2016) The Sustainability Theorem in the ESG Mechanism. Long Finance and London Accord, pp.1-29.

4. Hindman M (2018) The Internet Trap: How the Digital Economy Builds Monopolies and Undermines Democracy. Princeton University Press, Princeton, USA.

5. Tanaka H (2019) Rehabilitation of the Decentralization in the Centralizing Process of Global Communities. Journal of Global Issues and Solutions 19(3): 1-18.

6. Tanaka H (2019) Innovation on the Digital Economies and Sustainability of the Global Communities. Annals of social sciences \& management studies Juniper 4(2): 1-10.

7. Choudrie J, Tsatsou P, S Kruria (2018) Social Inclusion and Usability of ICT-Enable Services. Routledge, Abingdon, UK.

8. Tanaka H (2020) Chinese sustainable framework in the digitalized global communities. International Journal of Economic Policy Studies, Springer 14(2): 327-336.
9. Arrow K J (1973) Social Responsibility and Economic Efficiency. Public Policy 21: 303-317.

10. Tirole J (2001) Corporate Governance. Econometrica 69(1): 1-35.

11. Tanaka H (2004) Kigyo no Syakaiteki Sekinin no Keizai Riron (Japanese; Theoretical Analysis for Corporate Social Responsibility). Chikyuu Kankyu Report (Japanese; Global Environmental Policy in Japan), 9: $1-9$

12. Global Sustainable Investment Alliance (2019) Global Sustainable Investment Review 2018, pp,1-29.

13. Tanaka H (2019) Sustainable Governance of Marine Stakeholders. Oceanography \& Fisheries Open Access Journal, Juniper 11(1): 1-4.

14. Tanaka H (2020) Digital Revolution and Structural Reform of Stakeholders. Journal of Global Issues and Solutions 20(2): 1-7.

15. Tanaka H (2020) Digital Economic and Social Systems to be Featured by Stakeholders. Annals of social sciences \& management studies, Juniper 5(4): 86-94.

16. Tanaka H (2021) Green Bonds Issuance and Chinese Sustainable Governance. Long Finance and London Accord, pp:1-16.

17. Richardson HW, Nam CW (2014) Shrinking Cities A global perspective. Routledge, NY, USA.

18. Rifkin J (2014) The Zero Marginal Cost Society: The internet of Things, The Collaborative Commons, and The Eclipse of Capitalism. St. Martin's Press, New York, USA.

19. Oskam JA (2019) The future of Airbnb and 'Sharing Economy': The Collaborative Consumption of our Cities. Channel View Publications, Bristol, UK.

20. Paus E ed (2018) Confronting Dystopia: The New Technological Revolution and the Future of Work. Cornel University Press, New York, USA. 
21. Cassiers I, Maréchal K, Méda D ed (2018) Post-growth Economics and Society: Exploring the Paths of a Social and Ecological Transition. Routledge, Abingdon, UK.

22. Baecker RM (2019) Computers and Society: Modern Perspectives Oxford University Press, Oxford, UK.

23. The Climate Bonds Initiative and China Central Depository \& Clearing Research Centre (2020) China Green Bond Market :2019 Research Report.

24. Coase RH (1937) The Nature of the Firm. Economica 4(16): 386-405.
25. Williamson OE (1975) Markets and Hierarchies: Analysis and Antitrust Implication. The Free Press.

26. Williamson OE (1986) Economic Organization: Firms, Markets and Policy Control. Wheatsheaf Books, Brighton, UK.

27. Williamson OE (ed.), (1990) Industrial Organization. Edward Elgar Publishing, Cheltenham, UK.

28. Tanaka H (2021) Digital Industrial Revolution and an Index of Transaction Cost. American Journal of Novel Research in Sciences. Crimson Publishers 8(1): 1-2.

Your next submission with Juniper Publishers
will reach you the below assets
- Quality Editorial service
- Swift Peer Review
- Reprints availability
- E-prints Service
- Manuscript Podcast for convenient understanding
- Global attainment for your research
- Manuscript accessibility in different formats
( Pdf, E-pub, Full Text, Audio)
- Unceasing customer service
Track the below URL for one-step submission
https://juniperpublishers.com/online-submission.php

